\title{
Mutation analysis in the fibroblast growth factor 14 gene: frameshift mutation and polymorphisms in patients with inherited ataxias
}

\author{
Andreas Dalski ${ }^{1}$, Jassemien Atici ${ }^{1}$, Friedmar R Kreuz ${ }^{2}$, Yorck Hellenbroich ${ }^{1}$, \\ Eberhard Schwinger ${ }^{1}$ and Christine Zühlke ${ }^{*, 1}$
}

\author{
${ }^{1}$ Institute for Human Genetics, University of Luebeck, Germany; ${ }^{2}$ Institute of Clinical Genetics, University of Dresden, \\ Germany
}

The spinocerebellar ataxias (SCAs) with autosomal dominant inheritance are a group of neurodegenerative disorders with overlapping as well as highly variable phenotypes. Genetically, at least $\mathbf{2 5}$ different loci have been identified. Seven SCAs are caused by CAG trinucleotide repeat expansions, for 13 the chromosomal localization is known solely. Recently, a missense mutation in the fibroblast growth factor 14 gene (FGF14) has been reported in a Dutch family with a new dominantly inherited form of SCA. To evaluate the frequency of mutations in the FGF14 gene, we performed molecular genetic analyses for the five exons in 208 nonrelated familial ataxia cases and 208 control samples. In one patient, we detected a novel single base pair deletion in exon 4 (c.487delA) creating a frameshift mutation. In addition, we found DNA polymorphisms in exon $1 \mathrm{a}, 4$, and 5 , an amino-acid exchange at position 124 , as well as a single-nucleotide polymorphism in the $3^{\prime}$-untranslated region of exon 5 .

European Journal of Human Genetics (2005) 13, 118-120. doi:10.1038/sj.ejhg.5201286

Published online 6 October 2004

Keywords: spinocerebellar ataxia; ADCA; FGF14; mutation analysis

\section{Introduction}

For the autosomal dominantly inherited cerebellar ataxias (ADCA), 25 genetic loci have been identified by linkage analysis and mutations in $\geq 12$ of the corresponding genes have been reported. Molecular analysis of these genes revealed expansion of tri- or pentanucleotide repeats causing 10 spinocerebellar ataxia (SCAs). Recently, point mutations in the genes for the protein kinase $\mathrm{C} \gamma$ (PRKCG) and the fibroblast growth factor 14 (FGF14) have been found to be associated with forms of ADCA. ${ }^{1,2}$

FGF14 is a member of a subclass of fibroblast growth factors that is expressed in the developing and adult central nervous system. ${ }^{3}$ The FGF14 gene is located at chromo-

*Correspondence: Dr C Zühlke, Institut für Humangenetik, Ratzeburger Allee 160, University of Luebeck, Lübeck D-23538, Germany. Tel: + 49451 500 2622; Fax: + 49451500 4187; E-mail: zuehlke@uni-luebeck.de Received 26 May 2004; revised 15 July 2004; accepted 12 August 2004 some 13q34 and composed of five exons. Alternatively spliced transcript variants, differing in exon 1, have been found for this gene. ${ }^{4}$ Members of the FGF family show broad mitogenic and cell survival activities, and are involved in a variety of biological processes, including embryonic development, cell growth, morphogenesis, tissue repair, tumor growth and invasion. ${ }^{5}$

To evaluate the frequency for FGF14 mutations, we screened 208 samples of unrelated patients with familial history of ataxia but exclusion of repeat expansions at the SCA loci and 208 control samples for sequence variations within the coding region.

Patients and methods

Subjects

We studied 208 patients with familial ataxia but without repeat expansions in all previously identified SCA genes 
and 208 unaffected individuals of German origin. After having obtained informed consent for genetical analyses, total genomic DNA was extracted from peripheral blood leukocytes by standard protocols. ${ }^{6}$

\section{PCR and dHPLC analysis}

All exons (1a, 1b, 2, 3, 4, and 5) of FGF14 including flanking intron sequences have been amplified with primers and PCR protocol settings published. ${ }^{2}$ PCR product (100-150 ng) was analyzed for the presence of heteroduplexes using the dHPLC 3500HT WAVE system (Transgenomic). After denaturation for $5 \mathrm{~min}$ at $95^{\circ} \mathrm{C}$, amplicons were gradually cooled and incubated for $15 \mathrm{~min}$ at $50^{\circ} \mathrm{C}$ followed by a rapid chill to $4^{\circ} \mathrm{C}$. Buffers according to the recommendation of the manufacturer contain $0.1 \mathrm{M}$ triethylamonium acetate (TEAA) (buffer A) and 0.1 M TEAA with 25\% acetonitrile (buffer B). Melting profiles of each PCR product sequence were predicted with the Navigator 1.35 software (Transgenomic). According to these profiles two different temperatures for each exon (exon 1a: 65 and $67^{\circ} \mathrm{C}$; exon 1 b: 57 and $58^{\circ} \mathrm{C}$; exon 2: 55 and $59^{\circ} \mathrm{C}$; exon 3 : 55 and $57^{\circ} \mathrm{C}$; exon 4: 55 and $56^{\circ} \mathrm{C}$; exon 5: 58 and $59^{\circ} \mathrm{C}$ ) were chosen for dHPLC mutation analysis.

\section{Sequence analysis}

PCR products of samples with significant changes in dHPLC eluation peak patterns were sequenced on both strands by a commercial sequencing service (MWG BIO$\mathrm{TECH}$, Ebersberg, Germany). Finally, sequences and sequence profiles were checked manually and computationally in comparison to the FGF14 genomic and cDNA database sequences (Acc. NT_009952, NM_004115).

\section{Case report}

A mutation was found in an 18-year-old male patient with a mild mental retardation (IQ 70), an inborn strabismus, and red-green color vision defect. Screening of inborn errors of metabolism was negative. His motor development was normal until the age of 12 years, when his mother noticed slowly progressing gait disturbances, memory loss, and a depressive mood. Clinical examinations at 13 years showed truncal and gait ataxia, small-amplitude tremor in both hands, gaze-evoked nystagmus, and pes cavus. Nerve conduction studies revealed mild sensory axonal neuropathy. A cerebral MRI, intensive blood and liquor tests including vitamin E, immunglobulins, and coeruloplasmin were without pathological findings. Cytogenetic analysis showed a normal male karyotype $46, \mathrm{XY}$, molecular genetic testing for fragile $\mathrm{X}$ syndrome, Friedreich ataxia, SCA1, 2, $3,6,7,10,12$, and 17 was negative.

The patient's father also presented gait disturbances, memory loss, and pes cavus. He died of an anaplastic astrocytoma a few years ago. Unfortunately, neither detailed clinical information nor DNA is available.

\section{Results and discussion}

Molecular analyses for the FGF14 gene revealed six different DNA variations in 22 out of 416 samples (patients and control individuals). Two of the six variations result in a change at amino-acid level (Table 1).

In addition to the single-nucleotide polymorphism (SNP) at cDNA position 123, a heterozygous DNA variation resulting in a missense mutation or protein polymorphism was found in exon 1a. This genotype is present in three of the patients as well as in one control individual. Analysis of the c. $124 \mathrm{G}>\mathrm{T}$ variation in a family with affected twins detected the single-nucleotide change in a healthy parent and in one of the affected children but not in the twin. Therefore, the predictable amino-acid change from glycine to cysteine at position 42 will present a rare protein polymorphism rather than a pathogenic mutation.

Interestingly, one patient with ataxia and mild mental retardation carries heterozygous a single basepair deletion (delA) at position 487, leading to a frameshift mutation (p.Asp163fsX12) and a premature truncation of the protein missing one-third of amino-acid residues. The presented phenotype is consistent with the described family. ${ }^{2}$ The juvenile age of onset in the patient with the frameshift mutation points to larger phenotypical variations depending

Table 1 Mutations and SNPs in FGF14

\begin{tabular}{|c|c|c|c|c|c|c|}
\hline Exon & DNA variation & Mutation & CSNP & SNP & Number of patients & Number of controls \\
\hline $1 \mathrm{a}$ & $\begin{array}{l}\text { c. } 123 C>T \\
\text { c. } 124 G>T\end{array}$ & & $\begin{array}{l}\text { p.Asn41 } \\
\text { p.Gly42Cys }\end{array}$ & & $\begin{array}{l}1 \\
3\end{array}$ & $\begin{array}{l}2 \\
1\end{array}$ \\
\hline 4 & $\begin{array}{l}\text { c. } 487 \mathrm{del} A \\
\text { c. } 543 \mathrm{~T}>\mathrm{C}\end{array}$ & p.Asp $163 f \mathrm{f} X 12$ & p.Ala181 & & $\begin{array}{l}1 \\
2\end{array}$ & - \\
\hline 5 & $\begin{array}{l}\text { c. } 693 G>T \\
\text { c. } 775 G>A\end{array}$ & & p.Ala231 & $3^{\prime}$-UTR & $\begin{array}{l}2 \\
8\end{array}$ & $\overline{2}$ \\
\hline
\end{tabular}

SNP: single-nucleotide polymorphism; CSNP: SNP located in the coding region; $3^{\prime}$-UTR $=3^{\prime}$-untranslated region.

Nucleotide +1 is the A of the ATG translation initiation codon. 
on the mutation type or position within the FGF14 gene. Truncation of one allele resulting in hemizygous expression could be responsible for an early age of onset. On the other hand, variations of the FGF14 gene may be correlated with inherited mental retardation. Therefore, our findings strongly underline the evidence of FGF14 mutations involved in ataxia with neurodegeneration or mental impairment.

The cSNPs c.543T $>C$ and c.693G $>$ T do not result in amino-acid substitutions. However, both DNA sequence variations were found exclusively in patients - not in control samples - and produce a more frequently used codon for alanine in humans. Owing to the altered codon usage, the translation of the transcript may be enhanced resulting in an increased amount of FGF14 in these persons. Therefore, it could be speculated that overexpression of FGF14 is correlated with a disease phenotype.

Nevertheless, autosomal dominant FGF14 mutations are in contrast to the recessive Fgf14 knockout mouse model. ${ }^{7}$ These mice show ataxia and paroxysmal dyskinesia. Up to now, little is known about the molecular function of FGF14 and it is not excluded that different mutations produce pathological and differing phenotypes correlating with dominant or recessive inheritance. For example, dominant or recessive forms of Charcot-Marie-Tooth disease may be caused by mutations in the PMP22 gene. ${ }^{8-10}$

Thus, screening for FGF14 DNA variations in families with inherited ataxias may elucidate these complex events. However, molecular genetic analyses may be complicated by polymorphisms as present within the coding region as well as within the $3^{\prime}$-untranslated region in 17 of the 208 patients (Table 1). The assessment of SNPs should not be difficult in comparison to the interpretation of missense variations.

\section{Acknowledgements}

We thank all patients for providing blood samples for scientific research and their clinicians for collecting them. This work was supported by the Deutsche Forschungsgemeinschaft (DFG: ZU 136/11) and the German Heredo-Ataxia Society (DHAG), whose cooperation is essential in our work.

\section{References}

1 van de Warrenburg BP, Verbeek DS, Piersma SJ et al: Identification of a novel SCA14 mutation in a Dutch autosomal dominant cerebellar ataxia family. Neurology 2003; 61: 1760-1765.

2 van Swieten JC, Brusse E, de Graaf BM et al: A mutation in the fibroblast growth factor 14 gene is associated with autosomal dominant cerebellar ataxia. Am J Hum Genet 2003; 72: 191-199.

3 Smallwood PM, Munoz-Sanjuan I, Tong P et al: Fibroblast growth factor (FGF) homologous factors: new members of the FGF family implicated in nervous system development. Proc Natl Acad Sci USA 1996; 93: 9850-9857.

4 Wang Q McEwen DG, Ornitz DM: Subcellular and developmental expression of alternatively spliced forms of fibroblast growth factor 14. Mech Dev 2000; 90: 283-287.

5 Akai J, Storey K: Brain or brawn: how FGF signaling gives us both. Cell 2003; 115: 510-512.

6 Miller SA, Dykes DD, Polesky HF: A simple salting out procedure for extracting DNA from human nucleated cells. Nucl Acids Res 1988; 16: 1215

7 Wang $\mathrm{Q}$ Bardgett ME, Wong $\mathrm{M}$ et al: Ataxia and paroxysmal dyskinesia in mice lacking axonally transported FGF14. Neuron 2002; 35: 25-38.

8 Joo IS, Ki CS, Joo SY, Huh K, Kim JW: A novel point mutation in PMP22 gene associated with a familial case of Charcot-MarieTooth disease type $1 \mathrm{~A}$ with sensorineural deafness. Neuromuscul Disord 2004; 14: 325-328.

9 Thiel CT, Kraus C, Rauch A, Ekici AB, Rautenstrauss B, Reis A: A new quantitative PCR multiplex assay for rapid analysis of chromosome 17p11.2-12 duplications and deletions leading to HMSN/HNPP. Eur J Hum Genet 2003; 11: 170-178.

10 Roa BB, Garcia CA, Pentao L et al: Evidence for a recessive PMP22 point mutation in Charcot-Marie-Tooth disease type 1A. Nat Genet 1993; 5: 189-194. 